\title{
RESEARCH
}

\section{Sex- and age-based differences in the delivery and outcomes of critical care}

\author{
Robert A. Fowler MDCM MS, Natasha Sabur MD, Ping Li PhD, David N. Juurlink MD MSc, \\ Ruxandra Pinto PhD, Michelle A. Hladunewich MD MS, Neill K.J. Adhikari MDCM MS, \\ William J. Sibbald MD MPH, Claudio M. Martin MD MSc
}

\section{ABSTRACT}

Background: Previous studies have suggested that a patient's sex may influence the provision and outcomes of critical care. Our objective was to determine whether sex and age are associated with differences in admission practices, processes of care and clinical outcomes for critically ill patients.

Methods: We used a retrospective cohort of 466792 patients, including 24778 critically ill patients, admitted consecutively to adult hospitals in Ontario between Jan. 1, 2001, and Dec. 31, 2002. We measured associations between sex and age and admission to the intensive care unit (ICU); use of mechanical ventilation, dialysis or pulmonary artery catheterization; length of stay in the ICU and hospital; and death in the ICU, hospital and 1 year after admission.

Results: Of the 466792 patients admitted to hospital, more were women than men $(57.0 \%$ v. $43.0 \%$ for all admissions, $p<0.001 ; 50.1 \%$ v. $49.9 \%$ for nonobstetric admissions , $p<$ 0.001). However, fewer women than men were admitted to ICUs (39.9\% v. 60.1\%, $p<0.001$ ); this difference was most pronounced among older patients (age $\geq 50$ years). After adjustment for admission diagnoses and comorbidities, older women were less likely than older men to receive care in an ICU setting (odds ratio [OR] 0.68, 95\% confidence interval [CI] 0.66-0.71). After adjustment for illness severity, older women were also less likely than older men to receive mechanical ventilation (OR $0.91,95 \% \mathrm{Cl} 0.81-0.97$ ) or pulmonary artery catheterization (OR $0.80,95 \% \mathrm{Cl} 0.73-0.88$ ). Despite older men and women having similar severity of illness on ICU admission, women received ICU care for a slightly shorter duration yet had a longer length of stay in hospital (mean 18.3 v. 16.9 days; $p=0.006$ ). After adjustment for differences in comorbidities, source of admission, ICU admission diagnosis and illness severity, older women had a slightly greater risk of death in the ICU (hazard ratio 1.20, $95 \% \mathrm{Cl} \mathrm{1.10-1.31)} \mathrm{and} \mathrm{in} \mathrm{hospital} \mathrm{(hazard} \mathrm{ratio} \mathrm{1.08,}$ $95 \% \mathrm{Cl} 1.00-1.16)$ than did older men.

Interpretation: Among patients 50 years or older, women appear less likely than men to be admitted to an ICU and to receive selected life-supporting treatments and more likely than men to die after critical illness. Differences in presentation of critical illness, decision-making or unmeasured confounding factors may contribute to these findings.

Une version française de ce résumé est disponible à l'adresse www.cmaj.ca/cgi/content/full/I77/I2/I5I3/DCI

\section{CMAJ 2007;177(12):1513-9}

Published at www.cmaj.ca on Nov. I4, 2007.

$\mathrm{I}$ $\mathrm{t}$ is generally believed that access to an intensive care unit (ICU), the care received and subsequent clinical outcomes are determined primarily by need and severity of illness. However, in other areas of health care, sociodemographic characteristics have been found to influence treatment decisions and care delivery. ${ }^{1-6}$ For example, women are believed to have a lower incidence of coronary artery disease than men ${ }^{2}$ however, they are also less likely to undergo intensive evaluation and treatment for this condition and may have a higher rate of early mortality after acute myocardial infarction. ${ }^{7,8}$ Previous studies from various jurisdictions have suggested that there may be sex-based differences in critical illness and ICU admission patterns, ${ }^{3,4,6,9}$ although there have been no consistent findings of sex-based differences in the provision of care or clinical outcomes. . $^{1,3,4,6,10-12}$

The Canadian health care system is based on the principle of equal access for all citizens. This presents a unique opportunity to explore sex-related differences in ICU care. We hypothesized that age and sex might be associated with differences in

From the Interdepartmental Division of Critical Care Medicine (Fowler, Adhikari, Sibbald) and the Department of Medicine (Fowler, Juurlink, Hladunewich, Adhikari, Sibbald), University of Toronto and Sunnybrook Health Sciences Centre, Toronto, Ont.; the Faculty of Medicine (Sabur), University of Calgary, Calgary, Alta.; the Institute of Clinical and Evaluative Sciences (Li, Juurlink), Toronto, Ont.; the Department of Critical Care Medicine (Pinto) and the Division of Nephrology (Hladunewich), Sunnybrook Health Sciences Centre, Toronto, Ont.; and the Department of Medicine, University of Western Ontario, and the Centre for Critical Illness Research, Lawson Health Research Institute, London Health Science Centre (Martin), London, Ont. 
admission practices, processes of care and clinical outcomes for critically ill patients, and we explored these relations over a 2-year period in a diverse sample of hospitals in Ontario.

\section{Methods}

\section{Study population}

We obtained data on admission demographics, process of care and outcomes from hospitals and ICUs that are part of the Canadian Critical Care Research Network (CCRNet), a collaboration of urban and nonurban primary, secondary and tertiary care facilities. ${ }^{13}$ This database provided information on all patients admitted to adult ICUs in study hospitals from Jan. I, 200I, to Dec. 3I, 2002. We chose this 2-year period to minimize effects of seasonal variation in disease patterns and longer-term temporal trends and to allow sufficient follow-up. We restricted our cohort to Ontario hospitals to be able to merge the data set with other administrative databases. Of $\mathrm{I} 3$ participating centres, 4 were teaching and 9 were community hospitals. The median number of ICU beds was I4 (range 6-30); the median number of hospital beds was 36r (range $177-600$ ).

Information was collected by trained data abstractors, entered into an electronic database and stored in a central repository. All data were examined for accuracy and completeness and were subjected to an iterative process of reconfirmation that has been found to have high interobserver reliability and validity. ${ }^{14}$

The research ethics board of the Sunnybrook Health Sciences Centre approved this study.

\section{Data collection}

We collected data on demographic and physical characteristics (sex, age, height, weight); medical, surgical and specific diagnoses and comorbid conditions (based on International Classification of Diseases, 9th or Ioth revision, codes), from which the Deyo adaptation of the Charlson Comorbidity Index ${ }^{15}$ was calculated; diagnosis on ICU admission; source of ICU admission (e.g., emergency department, operating room, ward, other hospital); acute care variables necessary for the calculation of the APACHE (Acute Physiologic And Chronic Health Evaluation) II and III scores, which indicate severity of illness $;{ }^{16}$ duration of ICU and hospital stay; and survival status at ICU and hospital discharge. We included patients admitted more than once in the analyses by adjusting for non-independence of observations.

To evaluate critical care provided and to determine longterm health outcomes, we linked each patient's record in the Canadian Critical Care Research Network with 3 populationbased administrative databases. The Canadian Institute for Health Information database includes detailed diagnostic and demographic information on all hospital admissions. The Ontario Health Insurance Program database includes billing claims from physicians for such procedures as hemodialysis, pulmonary artery catheterization and mechanical ventilation. Finally, the Registered Persons Database includes demographic and vital statistics on all Ontario residents ever issued a health card. These databases are routinely combined using encrypted health card numbers to study outcomes at the patient level. ${ }^{10,12}$ We successfully linked these data sets for 2I 225
$(85.7 \%)$ of the critically ill patients in our cohort. There were no substantial differences in the proportion of women and men between the linked ( $40 \%$ women, $60 \%$ men) and unlinked ( $4 \mathrm{I} \%$ women, $59 \%$ men) records. Because catchment areas for each study hospital and the corresponding population size and sex distribution are not fixed, we chose to adjust for the known sex-specific population differences in the overall Ontario population and expressed admission rates as per Ioo 000 of the Ontario population, by sex and age decade.

\section{Statistical analysis}

We compared characteristics of patients using Student's $t$ test and the $\chi^{2}$ test. We used multiple logistic regression analysis to examine the relation between sex and admission to the ICU, with adjustment for Charlson Comorbidity Index score, source of ICU admission and diagnosis on ICU admission. We also examined the relation between sex and technological care received (newly instituted mechanical ventilation, pulmonary artery catheterization or hemodialysis), with adjustment for APACHE III score and diagnosis on ICU admission. We used proportional hazards modelling to examine the relation between sex and mortality during ICU and hospital stay and up to I year after admission, with adjustment for Charlson Comorbidity Index score, diagnosis on ICU admission, source of ICU admission and APACHE III score. We examined predictor variables and potential confounders for multicollinearity using a correlation matrix to ensure no correlations above 0.80 . We confirmed proportional hazards assumptions using log-log survival curves and a goodness-of-fit test. We followed the common practice of considering no more than I independent variable for every Io patients who experienced an event of interest. ${ }^{17}$ We limited our comparisons to the a priori specified explanatory variables of sex and specific potential confounders or effect modifiers, including age ( $\geq 50$ or $<50$ years, which is approximately the mean age of menopause in Canada and corresponds to age groupings in other studies), ${ }^{4}$ diagnosis on ICU admission, source of ICU admission, Charlson Comorbidity Index score and APACHE III score. All statistical tests were 2-tailed, and we used a $p$ value of 0.05 as the threshold for statistical significance.

\section{Results}

\section{Study population}

Between Jan. I, 200I, and Dec. 3I, 2002, 466792 patients were admitted to the study hospitals. Overall, $57.1 \%$ of the patients were women and $42.9 \%$ were men $(p<0.00 I)$ (Table I). Medical diagnoses accounted for $57.2 \%$ of the admissions, surgical diagnoses for $28.8 \%$ and obstetric diagnoses for $14.0 \%$. Of the patients admitted for nonobstetric reasons, $50.1 \%$ were women and $49.9 \%$ men $(p<0.001)$. The mean age of the patients admitted to hospital was 44.2 (standard deviation [SD] 35.0) years. We observed a greater number of admissions involving women than men among patients 50 years or older.

\section{Admissions to intensive care units}

There were 24778 consecutive admissions to ICUs during the study period. At the time of hospital admission, the mean Charlson Comorbidity Index score was the same for men and 
women (Table 2). Although men accounted for about half (49.9\%) of the nonobstetric hospital admissions, they accounted for $60.1 \%$ of the admissions to ICUs. This difference was more pronounced with increasing age (Figure I).

At the time of ICU admission, the male and female patients were of comparable age and had similar severity of illness, as measured by the APACHE II and III scores (Table 2). Compared with men, women were more frequently admitted to ICU from an emergency department, hospital ward or other hospital. A higher proportion of women than of men were admitted because of a medical illness; the reverse was true for admissions after elective surgery, with more men than women being admitted.

Although the proportion of admissions due to specific diagnoses varied according to sex, greater numbers of men than of women were admitted to an ICU with a medical diagnosis or a nonobstetric surgical diagnosis (Table 2). After adjusting for Charlson Comorbidity Index score, source of ICU admission, medical or surgical diagnosis and each of the 50 most common diagnoses for hospital admission, we found that older women (age 50 years or more) were significantly less likely than older men to be admitted to an ICU (odds ratio [OR] $0.68,95 \%$ confidence interval [CI] o.66-0.7I; $p<$ $0.00 \mathrm{I})$. This finding persisted after we excluded patients with an obstetric-gynecologic diagnosis.

\section{Diagnostic and therapeutic services provided}

We found that significantly more critically ill men than women received mechanical ventilation $(57.8 \%$ v. $52.3 \% ; p<0.00 I)$ and pulmonary artery catheterization (29.8\% v. $20.3 \% ; p<0.00 \mathrm{I})$; we found no significant difference for hemodialysis (Table 3 ). These findings persisted after we adjusted for severity of illness by APACHE III score (odds of women receiving mechanical ventilation: OR 0.9I, 95\% CI 0.8I-0.97, $p=0.005$; pulmonary artery catheterization: $\mathrm{OR} 0.80,95 \% \mathrm{CI} 0.73-0.88, p<0.001$; and hemodialysis: OR $0.87,95 \%$ CI $0.67-$ I.I2, $p=0.28$ ). Similar differences were found for both medical and surgical diagnoses and among both teaching and community hospitals. Because the differences may have been due to sex-discrepant practices of

Table 1: Characteristics of 466792 patients admitted to hospitals in Ontario between Jan. 1, 2001, and Dec. 31, 2002

\begin{tabular}{lcc}
\hline & \multicolumn{2}{c}{ No. (\%) of patients* } \\
\cline { 2 - 3 } & \multicolumn{1}{c}{$\begin{array}{c}\text { Women } \\
n=266619\end{array}$} & $\begin{array}{c}\text { Men } \\
n=200173\end{array}$ \\
\hline Characteristic & $43.3(34.3)$ & $45.3(35.9)$ \\
\hline Age, yr, mean (SD) & $159820(59.9)$ & $93776(46.8)$ \\
\hline $\begin{array}{l}\text { No. of admissions } \\
\text { Patients }<50 \text { yr }\end{array}$ & $106799(40.1)$ & $106397(53.2)$ \\
\hline $\begin{array}{l}\text { Patients } \geq 50 \text { yr } \\
\text { Type of admission }\end{array}$ & $132352(49.6)$ & $134884(67.4)$ \\
\hline $\begin{array}{l}\text { Medical } \\
\text { Surgical }\end{array}$ & $69015(25.9)$ & $65289(32.6)$ \\
\hline Obstetric & $65252(24.5)$ & - \\
\hline
\end{tabular}

Note: SD = standard deviation.

*Unless stated otherwise. a small number of high-volume centres, we compared procedure rates between men and women at centres with high and low volumes but found generally consistent patterns.

\section{Clinical outcomes}

Despite men and women 50 years or older having similar severity of illness on ICU admission, women received ICU care for a slightly shorter duration yet had a longer length of

Table 2: Characteristics of 24778 patients admitted to intensive care units in the study hospitals between Jan. 1, 2001, and Dec. 31, 2002

\begin{tabular}{|c|c|c|}
\hline \multirow[b]{2}{*}{ Characteristic } & \multicolumn{2}{|c|}{ No. (\%) of patients* } \\
\hline & $\begin{array}{l}\text { Women } \\
n=9878\end{array}$ & $\begin{array}{c}\text { Men } \\
n=14900\end{array}$ \\
\hline Age, yr, mean (SD) & $62.3(18.5)$ & $61(17.3)$ \\
\hline \multicolumn{3}{|l|}{ No. of admissions } \\
\hline Patients $<50 \mathrm{yr}$ & $2271(23.0)$ & $3346(22.5)$ \\
\hline Patients $\geq 50 \mathrm{yr}$ & $7607(77.0)$ & $11554(77.6)$ \\
\hline $\begin{array}{l}\text { Charlson Comorbidity Index } \\
\text { score at hospital admission, } \\
\text { mean (SD) }\end{array}$ & $1.45(1.68)$ & $1.45(1.69)$ \\
\hline $\begin{array}{l}\text { APACHE II score at ICU } \\
\text { admission, median (range) } \dagger\end{array}$ & $15(10-22)$ & $15(10-22)$ \\
\hline $\begin{array}{l}\text { APACHE III score at ICU } \\
\text { admission, median (range) } \dagger\end{array}$ & $52(36-75)$ & $52(36-75)$ \\
\hline \multicolumn{3}{|l|}{ Source of admission to ICU } \\
\hline Emergency department & $3476(35.2)$ & $4744(31.8)$ \\
\hline \multicolumn{3}{|l|}{ Operating room } \\
\hline Elective admission & $2651(26.8)$ & $5096(34.2)$ \\
\hline Emergent admission & $971 \quad(9.8)$ & $1464 \quad(9.8)$ \\
\hline Hospital ward & $1958(19.8)$ & $2497(16.8)$ \\
\hline Other hospital & $666 \quad(6.7)$ & $856 \quad(5.7)$ \\
\hline Other location & $156(1.6)$ & $243 \quad(1.6)$ \\
\hline \multicolumn{3}{|l|}{ Most responsible diagnosisł } \\
\hline Medical & $6263(63.4)$ & $8352(56.1)$ \\
\hline Cardiovascular & $1739(17.6)$ & $2459(16.5)$ \\
\hline Respiratory & $1608(16.3)$ & $1949(13.1)$ \\
\hline Gastrointestinal/hepatic & $390 \quad(3.9)$ & $674 \quad(4.5)$ \\
\hline Sepsis & 349 (3.5) & $463 \quad(3.1)$ \\
\hline Renal failure & 154 (1.6) & $187 \quad(1.3)$ \\
\hline Surgical & $3615(36.6)$ & $6548(43.9)$ \\
\hline Cardiovascular & $1352(13.7)$ & $3614(24.3)$ \\
\hline Gastrointestinal & $944 \quad(9.6)$ & 1171 (7.9) \\
\hline Respiratory/thoracic & $366 \quad(3.7)$ & $539 \quad(3.6)$ \\
\hline Trauma & 112 (1.1) & $324 \quad(2.2)$ \\
\hline Renal & 108 & $309 \quad(2.1)$ \\
\hline Gynecologic & 117 (1.2) & - \\
\hline
\end{tabular}

Note: $\mathrm{SD}=$ standard deviation, $\mathrm{APACHE}=$ Acute Physiologic And Chronic Health Evaluation.

*Unless stated otherwise.

tRange = lower quartile-upper quartile.

$\ddagger$ All medical and surgical admission diagnoses are displayed, in addition to a selected subset of these diagnoses. 
stay in hospital (mean I8.3 v. I6.9 days; $p=0.006$ ) (Table 4 ).

Among all of the patients admitted to hospital, we found that the in-hospital and I-year rates of death were slightly yet significantly higher among men than among women (Table 4). However, among critically ill patients, we observed the opposite: despite critically ill men and women 50 years or older having similar severity of illness, mortality was higher among women than among men in the ICU (15.4\% v. I2.7\%; $p<$ 0.00I) and in hospital (22.3\% v. I8.9\%; $p<0.001$ ) (Table 4). When we examined mortality by age decade and by 20 -year increments, we also found that mortality was significantly

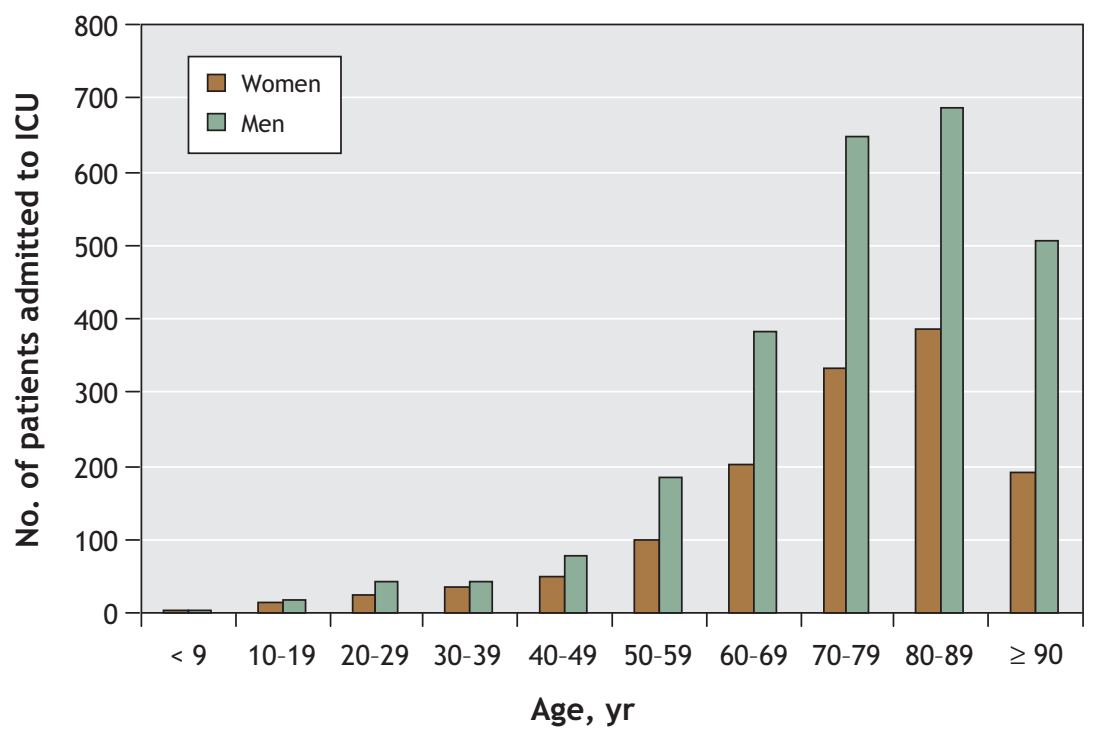

Figure 1: Age and sex distribution of 24778 patients admitted to intensive care units at study hospitals in Ontario between Jan. 1, 2000, and Dec. 31, 2001. Figures were adjusted for known sex-specific population differences in the overall Ontario population and are expressed as admission rates per 100000 of the Ontario population, by sex and age decade.

Table 3: Procedural and technological care delivered to patients admitted to intensive care units in the study hospitals

\begin{tabular}{|c|c|c|c|}
\hline \multirow[b]{2}{*}{ Care } & \multicolumn{2}{|c|}{ No. (\%) of patients } & \multirow[b]{2}{*}{$p$ value } \\
\hline & Women & Men & \\
\hline Mechanical ventilation & $4438 / 8493(52.3)$ & 7 363/12 732 (57.8) & $<0.001$ \\
\hline Surgical admissions & $1770 / 3191(55.5)$ & $3745 / 5859$ (63.9) & \\
\hline Medical admissions & $2668 / 5302(50.3)$ & $3618 / 6873(52.6)$ & \\
\hline $\begin{array}{l}\text { Pulmonary artery } \\
\text { catheterization }\end{array}$ & $1720 / 8493$ (20.3) & 3 794/12 732 (29.8) & $<0.001$ \\
\hline Surgical admissions & $1040 / 3191$ (32.6) & $2858 / 5859$ (48.8) & \\
\hline Medical admissions & 680/5 302 (12.8) & $936 / 6873$ (13.6) & \\
\hline Hemodialysis & $105 / 8166$ & 166/12 339 (1.4) & 0.75 \\
\hline Surgical admissions & $26 / 3141 \quad(0.8)$ & $37 / 5795 \quad(0.6)$ & \\
\hline Medical admissions & $79 / 5025 \quad(1.6)$ & $129 / 6544 \quad(2.0)$ & \\
\hline
\end{tabular}

Note: Figures are expressed as the proportion of critically ill patients in the study cohort for whom the required data were available. higher among critically ill older women than men (see Appendix I). Mortality did not differ significantly between younger critically ill women and men. We were able to determine the I-year mortality for $85.7 \%$ of the critically ill patients: it remained higher among women than among men ( $28.6 \%$ v. $25.2 \% ; p<0.001$ ) at I2 months after admission to owing to a significantly higher rate of death among older

To investigate how sex-related differences might depend on age, we prospectively chose a cutoff for age of 50 years. We found that there was an interaction between age and sex and that the chosen cutoff for age was appropriate, since differences generally increased after this age. A multiple logistic regression model that had in-ICU death as the outcome and included age, sex, APACHE III score (severity of illness) and all 2-way interactions revealed an expected interaction between age and severity of illness ( $p=$ 0.002). Therefore, we used separate models for patients less than 50 years old and those 50 years or older. We used proportional hazards modelling to examine the relation between sex and time to death, adjusting for APACHE III score, Charlson Comorbidity Index score, each of the 50 most common diagnoses and source of ICU admission. We found no effect of sex among patients less than 50 years. However, after adjusting for all other factors, we found a significant effect $(p<0.00 I)$ among older patients (Figure 2). Among older patients, being female was associated with a $20 \%$ increased risk of death in ICU (hazard ratio [HR] I.20, 95\% CI I.IO-I.3I), an 8\% increased risk of death in hospital (HR I.08, 95\% CI I.00-I.I6) and a 6\% (nonsignificant) increased risk of death over I year (HR I.06, 95\% CI I.00-I.I2).

\section{Interpretation}

In this large cohort of patients admitted to hospitals and ICUs in Ontario over a 2-year period, we found sex- and age-related differences in admissions to ICU and receipt of specific life-supporting interventions, as well as in short- and long-term outcomes. Women represented more than half of the patients admitted to hospital during the study period, a distribution similar to that of patients admitted to all Canadian hospitals during $2000-200 \mathrm{I}$ (58.0\% v. $42.0 \%$ ). ${ }^{18,19}$ The distribution of women and men admitted for nonobstetric reasons corresponded to the slight predominance of women in the Ontario (51. $1 \%$ ) and Canadian ( $51.0 \%)$ general populations during 200I. ${ }^{20}$ As well, the 
greater number of women than men among patients 50 years or older who were admitted to hospital corresponded to the slight female predominance in the general population that increases with age and to the proportion of patients admitted to other Canadian hospitals who were 50 years or older. ${ }^{18}$

However, despite more women than men 50 years or older being admitted to hospital, women were significantly less likely than men to receive care in an ICU. Moreover, although men and women had similar severity of illness at the time of ICU admission, women were less likely than men to receive mechanical ventilation and pulmonary artery catheterization for medical and surgical diagnoses. In addition, we found that, after adjusting for comorbidities, diagnosis on ICU admission and severity of illness, the rates of death in ICU and in hospital were higher among critically ill women 50 years or older than among their male counterparts.

As age increased, men were increasingly more likely than women to be admitted to ICU regardless of whether their diagnosis was medical or surgical and despite the fact that there are more women in the general population, that more women than men were admitted to the study hospitals and that severity of illness at the time of ICU admission was similar for men and women. This difference might be because in-hospital illness progresses differently for men and women. Although we accounted for the 50 most common diagnoses for hospital admission and used a well-validated comorbidity index to account for the possibility of different comorbidity-based severity of illness at the time of hospital admission, we found that older men were still more likely than older women to be admitted to an ICU. This makes any sex-related differences in population-based disease prevalence less likely to be the sole explanation for our findings. Other epidemiologic studies have observed similar sex-related differences. ${ }^{3,4,21}$

Our finding that critically ill women were less likely than critically ill men to receive mechanical ventilation and pulmonary artery catheterization is consistent with findings from other studies that showed men being more likely than women to receive invasive therapies. ${ }^{1,3}$ Although we found that men with acute renal failure more commonly received hemodialysis than did women, the difference was not significant. Similar observations have been reported in other acute care populations. ${ }^{5}$

Older men are known to have a higher risk of death than older women after admission to hospital. ${ }^{22}$ However, we found the opposite among critically ill patients: older women who were critically ill were more likely to die than critically ill men of similar age. This age-sex relation is consistent with findings from smaller studies. ${ }^{4,23}$ In previous studies, sex-related differences in outcomes among critically ill patients receiving mechanical ventilation were attenuated after adjustment for severity of illness; ${ }^{3,24}$ however, we found important residual sex- and age-related associations after making such adjustments.

Gender bias has been reported to affect treatment decisions in other fields and may also influence decisions about ICU admission. ${ }^{1,4,25}$ Sex-related differences may be due to differences in decision-making or preferences of the patients, their surrogate decision-makers or the health care team. For example, in a study of differences between men and women in the rate of hip and knee arthroplasty, women were found to have a greater need than men for joint replacement therapy, but despite equal willingness to undergo the procedure, they were less likely than men to discuss surgery with their physician, which led to less frequent recommendation for surgery. ${ }^{26}$ These differences increased with age. The Study to Understand Prognoses and Preferences for Outcomes and Risks of Treatments - a large multicentre observational study and clinical trial that examined critical care delivery at the end of life - similarly found that physician-patient communication regarding preferences for aggressiveness of care was suboptimal and pronounced among older patients. ${ }^{27,28}$ In Canada, women are generally both younger and have a longer life-expectancy than their spouses, which leads to elderly women more frequently assuming a role as caregiver or supporter of their older male partner. In contrast, at end of life, women are

Table 4: Length of stay in intensive care unit (ICU) and hospital, and mortality among study patients

\begin{tabular}{|c|c|c|c|c|c|c|c|c|c|}
\hline Outcome & $\begin{array}{l}\text { All women } \\
n=8493\end{array}$ & $\begin{array}{c}\text { All men } \\
n=12732\end{array}$ & $p$ value & $\begin{array}{c}\text { Women }<50 \mathrm{yr} \\
n=1971\end{array}$ & $\begin{array}{c}\text { Men }<50 y r \\
n=2832\end{array}$ & $p$ value & $\begin{array}{c}\text { Women } \geq 50 \mathrm{yr} \\
n=6522\end{array}$ & $\begin{array}{c}\text { Men } \geq 50 \mathrm{yr} \\
n=9900\end{array}$ & $p$ value \\
\hline \multicolumn{10}{|c|}{$\begin{array}{l}\text { Length of stay, } \\
\text { d, mean (SD) }\end{array}$} \\
\hline ICU & $4.7(9.5)$ & $4.8(12.8)$ & 0.56 & $4.2(11.0)$ & $4.5(15.3)$ & 0.57 & $4.8 \quad(9.0)$ & $4.9(12.0)$ & 0.78 \\
\hline Hospital & $17.4(24.2)$ & $16.4(24.8)$ & 0.006 & $14.4(22.1)$ & $14.9(28.6)$ & 0.49 & $18.3(24.7)$ & $16.9(23.8)$ & $<0.001$ \\
\hline In hospital & 7032 (2.6) & 7731 (3.9) & $<0.001$ & $497 \quad(0.3)$ & $614(0.7)$ & $<0.001$ & $6535 \quad(6.1)$ & 7117 (6.7) & $<0.001$ \\
\hline $\begin{array}{l}1 \mathrm{yr} \text { after } \\
\text { admission }\end{array}$ & 22716 (8.5) & $25559(12.8)$ & $<0.001$ & 2040 & $2202(2.4)$ & $<0.001$ & $20676(19.4)$ & $23357(22.0)$ & $<0.001$ \\
\hline \multicolumn{10}{|c|}{ Critically ill patients } \\
\hline In ICU & $1138(13.4)$ & $1466(11.5)$ & $<0.001$ & $135 \quad(6.8)$ & $207(7.3)$ & 0.54 & $1003(15.4)$ & $1259(12.7)$ & $<0.001$ \\
\hline
\end{tabular}

Note: $\mathrm{SD}=$ standard deviation. 
older than men and more likely to be widowed. This different social context may lead to different decisions about aggressiveness of end-of-life care by men and women or their families. Although previous studies have not found sex to be independently associated with the decision to withdraw specific life-supporting therapies, such as mechanical ventilation, there may be substantial differences in the decision process concerning initiation versus withdrawal of specific forms of ICU therapies. ${ }^{29,30}$ Even though such invasive therapies do not necessarily improve clinical outcomes, ${ }^{31}$ our findings suggest that differential care strategies may exist among older men and women.

There may also be plausible biological explanations for the differences in mortality we found between critically ill older men and women. Sex has been found to influence the expression, progression and outcome of many common medical conditions and can influence pharmacokinetics and responses to therapy. ${ }^{32,33}$ It may also influence susceptibility to immunologic disorders and responses to severe infections and sepsis. ${ }^{23,34}$ These factors may explain differential outcomes of critical illness. However, a consistent relation between critical

$\begin{array}{lcr}\text { All women } & & \\ \text { In ICU } & \text { HR }(95 \% \mathrm{Cl}) & p \text { value } \\ \text { Unadjusted } & 1.15(1.06-1.24) & 0.001 \\ \text { Adjusted } & 1.20(1.10-1.30) & <0.001 \\ \text { In hospital } & & \\ \quad \text { Unadjusted } & 1.09(1.02-1.16) & 0.009 \\ \text { Adjusted } & 1.09(1.01-1.16) & 0.020 \\ \begin{array}{llr}\text { 1 yr after admission } \\ \text { Unadjusted }\end{array} & 1.16(1.10-1.22) & <0.001 \\ \text { Adjusted } & 1.08(1.02-1.14) & 0.009\end{array}$

\section{Women $<50 \mathrm{yr}$}

$\begin{array}{ccc}\text { In ICU } & \text { HR }(95 \% \mathrm{Cl}) & p \text { value } \\ \text { Unadjusted } & 0.94(0.76-1.17) & 0.59 \\ \text { Adjusted } & 1.06(0.84-1.34) & 0.62 \\ \text { In hospital } & & \\ \text { Unadjusted } & 0.94(0.78-1.14) & 0.53 \\ \text { Adjusted } & 0.97(0.79-1.19) & 0.78 \\ \text { 1 yr after admission } & \\ \text { Unadjusted } & 1.03(0.87-1.20) & 0.76 \\ \text { Adjusted } & 1.04(0.88-1.23) & 0.67\end{array}$

\section{Women $\geq 50 \mathrm{yr}$}

$\begin{array}{ccc}\text { In ICU } & \text { HR }(95 \% \mathrm{Cl}) & p \text { value } \\ \text { Unadjusted } & 1.18(1.09-1.28) & <0.001 \\ \text { Adjusted } & 1.20(1.10-1.31) & <0.001 \\ \text { In hospital } & & \\ \text { Unadjusted } & 1.11(1.04-1.19) & 0.003 \\ \text { Adjusted } & 1.08(1.00-1.16) & 0.044 \\ \text { 1 yr after admission } & \\ \text { Unadjusted } & 1.20(1.13-1.26) & <0.001 \\ \text { Adjusted } & 1.06(1.00-1.12) & 0.06\end{array}$
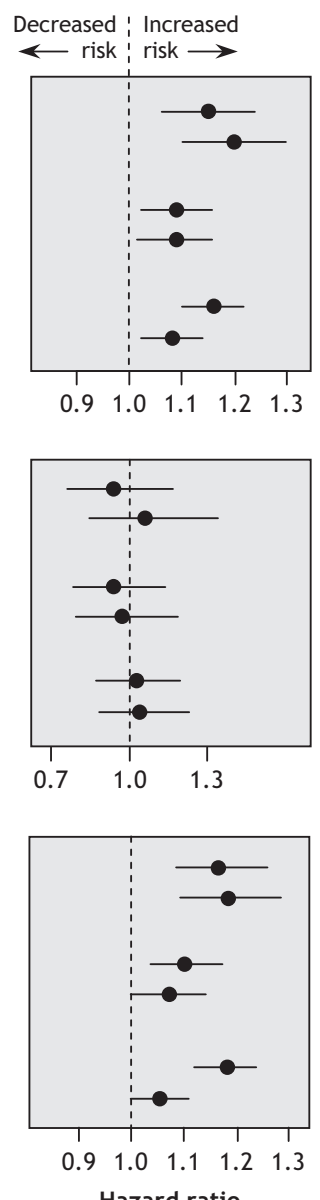

Hazard ratio

Figure 2: Unadjusted and adjusted hazard ratios for risk of death among critically ill women ( $v$. men) admitted to intensive care units (ICUs). (Adjustments were for Charlson Comorbidity Index score, APACHE III score [severity of illness], source of ICU admission and diagnosis on ICU admission.) illness and sex, immunologic response and clinical outcomes has not been established. ${ }^{23,35,36}$ Different estrogen or other sexrelated hormone levels and unique cytokine responses among younger and older men and women may explain in part the difference in mortality we observed. ${ }^{37}$ However, critical illness comprises a broad range of complex underlying conditions, and it is unlikely that a single or even a few simple sex-related biological differences apply equally and in all circumstances.

The strengths of our study include its large sample, the diverse nature of participating ICUs and patients, a detailed knowledge of severity of illness and comorbidities, and longterm outcome data. We were able to adjust for differences in acute physiology and chronic illnesses, as well as surgical versus medical admission diagnoses. We were also able to examine differences in the delivery of life-supporting care and determine the long-term outcomes for a large proportion of patients.

Our study had several limitations. Because it was observational, we were unable to establish causal relations. We also were unable to determine population prevalence rates for all ICU admission diagnoses and, thus, could not explore reasons for different admission rates among men and women for all conditions. Similarly, information was not available for all critically ill patients in all ICUs in Ontario. However, we used a broad spectrum of teaching and community hospitals and ICUs within a research network well known for its ability to capture valid and detailed information at the patient level. There may have been variables that we were unable to measure that had important effects on the reported associations. Finally, our results may not be generalizable to other jurisdictions, although patient demographics in our cohort are similar to those at other Canadian hospitals and our findings are consistent with reports of admission patterns and care received in other health care systems. ${ }^{4,5}$

In conclusion, we have shown that there may be important sex- and age-related differences in the provision of critical care and outcomes of critical illness within a health care system founded on the principle of equal access and opportunity for all patients. Further research is needed to determine whether these findings are due to sex-related differences in prevalence or response to critical illness, differences in preference for or access to intensive care, or other differences in the provision of care to critically ill patients.

This article has been peer reviewed.

Competing interests: None declared.

Contributors: All of the authors made substantial contributions to the conception and design, acquisition of data, or analysis and interpretation of data; drafted the article or revised it critically for important intellectual content; and gave final approval of the version to be published.

Acknowledgements: We are grateful for the contributions of the participating hospitals and members of the Canadian Critical Care Research Network as well as staff of the Institute of Clinical and Evaluative Sciences for their dedication to the betterment of population and patient care through research. We acknowledge the thoughtful review of the project methods and manuscript by Drs. Peter Dodek, Andreas Laupacis, Don Redelmeier and Eva Shimaoka. We dedicate this manuscript to the memory of Dr. William J. Sibbald: his passion was to understand critical illness, to improve critical care delivery and to mentor others to do the same.

Grant support was received from the Canadian Institutes of Health Research. Robert Fowler is a Career Scientist of the Ontario Ministry of Health and Long-term Care. 


\section{REFERENCES}

I. Raine R, Goldfrad C, Rowen $\mathrm{K}$, et al. Influence of patient gender on admission to intensive care. JEpidemiol Community Health 2002;56:418-23

2. Jousilahti P, Vartiainen E, Tuomilehto J, et al. Sex, age, cardiovascular risk factors and coronary heart disease: a prospective follow-up study of I4 786 middle-aged men and women in Finland. Circulation I999;99:1165-72.

3. Valentin A, Jordan B, Lang T, et al. Gender-related differences in intensive care: multiple-center cohort study of therapeutic interventions and outcome in critically ill patients. Crit Care Med 2003;3I:I90I-7.

4. Romo H, Amaral AC, Vincent JL. Effect of patient sex on intensive care unit survival. Arch Intern Med 2004; 64 :6I-5

5. Alter DA, Naylor CD, Austin PC, et al. Biology or bias: practice patterns and longterm outcomes for men and women with acute myocardial infarction. J Am Coll Cardiol 2002;39:1909-I6.

6. Martin GS, Mannino DM, Eaton S, et al. The epidemiology of sepsis in the United States from I979 through 2000. N EngI J Med 2003;348:I546-54.

7. Ayanian JZ, Epstein AM. Differences in the use of procedures between women and men hospitalized for coronary heart disease. N Engl J Med I99I;325:22I-5

8. Vaccarino V, Parsons L, Every NR, et al. Sex-based differences in early mortality after myocardial infarction. National Registry of Myocardial Infarction 2 Participants. NEngl J Med I999;34I:217-25

9. Iwashyna TJ Critical care use during the course of serious illness. Am J Respir Crit Care Med 2004; I70:98I-6.

Io. Needham DM, Bronskill SE, Sibbald WJ, et al. Mechanical ventilation in Ontario, I992-2000: incidence, survival, and hospital bed utilization of noncardiac surgery adult patients. Crit Care Med 2004;32:1504-9.

II. Kollef MH, O'Brien JD, Silver P. The impact of gender on outcome from mechanical ventilation. Chest I997; III:434-4I

I2. Dueck AD, Johnston KW, Alter D, et al. Predictors of repair and effect of gender on treatment of ruptured abdominal aortic aneurysm. J Vasc Surg 2004;39:784-7.

I3. Keenan SP, Martin CM, Kossuth JD, et al. The Critical Care Research Network: a partnership in community-based research and research transfer. J Eval Clin Pract 2000;6:15-22.

I4. Chen LM, Martin CM, Morrison TL, et al. Interobserver variability in data collection of the APACHE II score in teaching and community hospitals. Crit Care Med I999;27:1999-2004.

15. Deyo RA, Cherkin DC, Ciol MA. Adapting a clinical comorbidity index for use with ICD-9-CM administrative databases. J Clin Epidemiol 1992;45:613-9.

I6. Knaus WA, Wagner DP, Draper EA, et al. The APACHE III prognostic system. Risk prediction of hospital mortality for critically ill hospitalized adults. Chest I991;100: I6r9-20.

17. Katz MH. Multivariable analysis: a practical guide for clinicians. Cambridge (UK): Cambridge University Press; 1999.

18. Canadian Institute for Health Information. Inpatient hospitalizations for Canada, I995-1996 to 2006-2007: inpatient/acute admissions by province of facility location. Ottawa: The Institute. Available: http://secure.cihi.ca/cihiweb/dispPage.jsp ?cw_page $=$ statistics_results_topic_hospital_e\&cw_topic=Health\%2oServices\&cw _subtopic $=$ Hospital\%20Discharges (accessed 2007 Nov 3).

I9. Critical Care Research Network. Minimum Data Set. London (ON): The Network. Available: www.criticalcareresearch.net/mds/mdsabs.html (accessed 2005 Oct 30).
20. Age and sex, 20or counts for both sexes, for Canada, provinces and territories. In: Age and sex: highlight tables, $200 I$ census. Ottawa: Statistics Canada. Available: http: //wwwI2.statcan.ca/english/censusor/products/highlight/AgeSex/Page.cfm?Lang=E\& $\mathrm{Geo}=\mathrm{PR} \& V i e w=\mathrm{I} \&$ Code $=0 \&$ Table $=\mathrm{Ia} \&$ StartRec $=\mathrm{I} \&$ Sort $=2 \& \mathrm{BI}=$ Counts\&B2 $=$ Both $(\mathrm{ac}-$ cessed 2007 Oct 29).

2I. Le Gall JR, Lemeshow S, Saulnier F. A new simplified acute physiology score (SAPS II) based on a European/North American multicenter study. JAMA I993;270:2957-63.

22. Walter LC, Brand RJ, Counsell SR, et al. Development and validation of a prognostic index for I-year mortality in older adults after hospitalization. JAMA 2001;285:2987-94.

23. Eachempati SR, Hydo L, Barie PS. Gender-based differences in outcome in patients with sepsis. Arch Surg 1999;134:1342-7.

24. Epstein SK, Vuong V. Lack of influence on gender on outcomes of mechanically ventilated medical ICU patients. Chest I999;II6:732-9.

25. Garrouste-Orgeas M, Montuclard L, Timsit JF, et al. Predictors of intensive care unit refusal in French intensive care units: a multiple-center study. Crit Care Med 2005;33:750-5.

26. Hawker GA, Wright JG, Coyte PC, et al. Differences between men and women in the rate of use of hip and knee arthroplasty. N Engl J Med 2000;342:1016-22.

27. Covinsky KE, Fuller JD, Yaffe K, et al. Communication and decision-making in seriously ill patients: findings of the SUPPORT project. The Study to Understand Prognoses and Preferences for Outcomes and Risks of Treatments. J Am Geriatr Soc 2000;48(5 Suppl):S187-93.

28. Hamel MB, Davis RB, Teno JM, et al. Older age, aggressiveness of care, and survival for seriously ill, hospitalized adults. SUPPORT Investigators. Study to Understand Prognoses and Preferences for Outcomes and Risks of Treatments. Ann Intern Med I999;I3 I:72I-8.

29. Cook D, Rocker G, Marshall J, et al. Withdrawal of mechanical ventilation in anticipation of death in the intensive care unit. N Engl J Med 2003;349:II23-32.

30. Keenan SP, Busche KD, Chen LM, et al. A retrospective review of a large cohort of patients undergoing the process of withholding or withdrawal of life support. Crit Care Med I997;25:1324-3I.

3I. Sandham JD, Hull RD, Brant RF, et al. A randomized, controlled trial of the use of pulmonary-artery catheters in high-risk surgical patients. NEngIJMed 2003;348:5-I4.

32. McCarthy M. The gender gap in autoimmune disease. Lancet 2000;356:1088.

33. Schwartz JB. The influence of sex on pharmacokinetics. Clin Pharmacokinet 2003;42:107-2I.

34. Crabtree TD, Pelletier SJ, Gleason TG, et al. Gender-dependent differences in outcome after the treatment of infection in hospitalized patients. JAMA I999;282:2143-8.

35. Oberholzer A, Keel M, Zellweger R, et al. Incidence of septic complications and multiple organ failure in severely injured patients is sex specific. JTrauma 2000;48:932-7.

36. Brun-Buisson C, Meshaka P, Pinton P, et al. Episepsis: a reappraisal of the epidemiology and outcome of severe sepsis in French intensive care units. Intensive Care Med 2004;30:580-8

37. Angstwurm MW, Gaertner R, Schopohl J. Outcome in elderly patients with severe infection is influenced by sex hormones but not gender. Crit Care Med 2005;33:2786-93.

Correspondence to: Dr. Robert A. Fowler, Sunnybrook Health Sciences Centre, Rm. D478, 2075 Bayview Ave., Toronto ON $\mathrm{M}_{4} \mathrm{~N}_{3} \mathrm{M}_{5}$; fax 4I6 48o-6rgi; rob.fowler@sunnybrook.ca

Appendix 1: Clinical outcome for critically ill patients, by age group

\begin{tabular}{|c|c|c|c|c|c|c|c|}
\hline Age; sex & $\begin{array}{l}\text { No. of } \\
\text { patients }\end{array}$ & $\begin{array}{l}\text { Mortality in ICU, } \\
\text { no. (\%) of patients }\end{array}$ & $p$ value & $\begin{array}{c}\text { Mortality in hospital, } \\
\text { no. (\%) of patients }\end{array}$ & $p$ value & $\begin{array}{c}\text { Mortality } 1 \text { yr after } \\
\text { admission, no. (\%) } \\
\text { of patients }\end{array}$ & $p$ value \\
\hline \multicolumn{8}{|l|}{$<30 \mathrm{yr}$} \\
\hline Women & 583 & $24 \quad(4.1)$ & 0.17 & $28 \quad(4.8)$ & 0.11 & $37 \quad(6.3)$ & 0.19 \\
\hline Men & 893 & $51 \quad(5.7)$ & & $61 \quad(6.8)$ & & $73 \quad(8.2)$ & \\
\hline \multicolumn{8}{|l|}{$30-49 \mathrm{yr}$} \\
\hline Women & 1388 & 111 (8.0) & 0.96 & $145(10.4)$ & 0.98 & 220 (15.9) & 0.38 \\
\hline Men & 1939 & $156 \quad(8.0)$ & & 203 (10.5) & & 286 (14.7) & \\
\hline \multicolumn{8}{|l|}{$50-69 \mathrm{yr}$} \\
\hline Women & 2859 & $353(12.3)$ & $<0.001$ & $485(17.0)$ & $<0.001$ & 739 (25.8) & $<0.001$ \\
\hline Men & 5185 & $501 \quad(9.7)$ & & $694(13.4)$ & & $1089(21.0)$ & \\
\hline \multicolumn{8}{|l|}{$\geq 70 \mathrm{yr}$} \\
\hline Women & 3663 & 650 (17.7) & 0.028 & $971(26.5)$ & 0.07 & $1430(39.0)$ & 0.046 \\
\hline Men & 4755 & 758 (15.9) & & 1179 (24.8) & & $1761(37.0)$ & \\
\hline
\end{tabular}

Note: ICU = intensive care unit. 